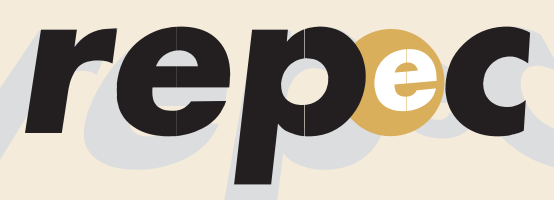

REPeC, Brasília, v. 8, n. 2, art. 6, p. 209-224, abr.jun. 2014 Disponível online em www.repec.org.br

\title{
Caso de Ensino
}

\section{JBA Cosméticos Ltda.:}

\section{manter ou fechar a loja Oeste?}

\section{Resumo}

Este caso tem como objetivo ilustrar o uso de conceitos e técnicas de custos relevantes para a análise de decisões políticas de longo prazo. Ele foi concebido para ser discutido nas disciplinas Contabilidade Gerencial ou Contabilidade de Custos nos cursos de graduação e de pós-graduação lato sensu em Ciências Contábeis, Administração e Engenharia da Produção. A JBA Cosméticos Ltda. é uma empresa de pequeno porte especializada na venda de cosméticos femininos. Em 2010, ela possuía três lojas, Norte, Sul e Oeste, e uma delas, a Oeste, vinha apresentando resultados insatisfatórios, a despeito do crescimento do setor de cosméticos. Incomodados com essa situação, os sócios precisavam decidir se fechariam, ou não, a loja deficitária. Para isso, tinham que comparar as receitas auferidas pela loja com os custos que lhes eram atribuíveis custos variáveis, custos fixos divisíveis e custos indivisíveis identificados. A determinação dos custos atribuíveis, como os alunos terão oportunidade de perceber ao responder às questões propostas, envolve um razoável grau de subjetividade. Essas questões também sugerem fatores qualitativos que não devem ser ignorados nesse tipo de decisão. Pode-se argumentar que as incertezas envolvidas em decisões, como a de fechar uma loja, são mais bem apreendidas por meio da análise de casos do que pela resolução de problemas.

Palavras-chave: decisões políticas de longo prazo, custos atribuíveis, relatórios gerenciais por segmento.

\begin{abstract}
Moacir Sancovschi
D. Sc. em Administração pela COPPEAD/

UFRJ e Professor Departamento de

Contabilidade e Curso de Mestrado e Doutorado em Ciências Contábeis da FACC/UFRJ. Contato: Av Pasteur, 250, Departamento de Contabilidade, Praia Vermelha, Urca, Rio de Janeiro-RJ CEP: 22290-240.
\end{abstract}

E-mail: msancov@facc.ufrj.br

\section{Marcus Vinicius Melo Moraes}

Mestre em Ciências Contábeis pela UFRJ e Professor Assistente da Faculdade de Administração e Ciências Contábeis da Universidade Federal do Rio de Janeiro (FACC/UFRJ) e Auditor-Fiscal da Receita Federal do Brasil. Contato: Av Pasteur, 250, Departamento de Contabilidade, Praia Vermelha, Urca, Rio de Janeiro-RJ CEP: 22290-240.

E-mail:mvmmoraes@facc.ufri.br

\section{Lidiano de Jesus Santos}

Mestre em Ciências Contábeis pela UFRJ e Contador do Banco Nacional de Desenvolvimento Econômico e Social BNDES. Contato: Av. Republica do Chile, 100 - Centro - Rio de Janeiro - RJ. CEP: 200331-917.

E-mail: lidianojesus@bol.com.br 


\section{Introdução}

A JBA Cosméticos Ltda. é uma empresa de pequeno porte especializada na venda de cosméticos femininos. Em 2010, ela possuía três lojas: Norte, Sul e Oeste. Uma delas, a Oeste, vinha apresentando resultados insatisfatórios a despeito do crescimento do setor de cosméticos. Desconfortáveis com essa situação, os sócios precisavam decidir com urgência se fechariam, ou não, a loja deficitária. Combinaram, então, fazer uma reunião no início de 2011 para por um ponto final nessa questão.

\section{A reunião}

De volta ao trabalho, após os feriados do fim do ano de 2010, João e Alice estavam reunidos no escritório da loja Norte, ouvindo com atenção as explicações de Bruno sobre o desempenho da loja Oeste da JBA Cosméticos Ltda.

Em 2010, a JBA possuía três lojas: Norte, Sul e Oeste. Das três, a Oeste era a que tinha o pior desempenho. Seus resultados financeiros, que nunca foram tão bons quanto os das demais, recentemente ficaram negativos. Por isso, os sócios decidiram avaliar o mérito de fechá-la.

Bruno era claramente favorável ao fechamento da loja e justificava sua posição com base nos resultados apurados em 2010 para a empresa, e para cada uma de suas lojas (Tabela 1). Nesse relatório, a loja voltou a apresentar prejuízo.

Tabela 1

Demonstração de Resultado do período findo em 31 de dezembro de 2010

\begin{tabular}{lcccc}
\cline { 2 - 5 } & Total & Loja Oeste & Loja Sul & Loja Norte \\
\hline Vendas & 12.000 .000 & 2.880 .000 & 4.800 .000 & 4.320 .000 \\
\hline Custo dos Produtos Vendidos & 6.628 .800 & 1.612 .800 & 2.640 .000 & 2.376 .000 \\
\hline Lucro Bruto & 5.371 .200 & 1.267 .200 & 2.160 .000 & 1.944 .000 \\
\hline Despesas Operacionais & & & & \\
\hline Despesas Totais de Vendas & 3.268 .000 & 925.600 & 1.260 .000 & 1.082 .400 \\
\hline Despesas Totais Administrativas & 1.608 .000 & 446.000 & 632.800 & 529.200 \\
\hline Despesas Totais & 4.876 .000 & 1.371 .600 & 1.892 .800 & 1.611 .600 \\
\hline Lucro (Prejuízo) Operacional Líquido & 495.200 & $(104.400)$ & 267.200 & 332.400 \\
\hline
\end{tabular}

Alice, que pouco entendia de Contabilidade, ponderou que todos tinham trabalhado muito para implantar a loja Oeste, e que talvez o fechamento da loja fosse precipitado, interrompendo uma trajetória que vinha produzindo ganhos crescentes para os três sócios.

João, um pouco mais pragmático, observou que a margem bruta percentual das três lojas era praticamente a mesma, e que o problema poderia estar nas elevadas despesas incorridas na loja Oeste ou na receita que ela estava auferindo. Como a receita vinha crescendo dentro do esperado, ele focou nas despesas, e perguntou ao Bruno o que achava do trabalho do gerente da loja. Bruno respondeu que o gerente tinha um temperamento excelente, era um profissional zeloso e que não havia indícios de que ele fosse displicente no controle das despesas.

João, então, perguntou por que as despesas da loja Oeste estavam tão elevadas. De fato, queria saber em quanto seriam reduzidas as despesas da JBA se aquela loja fosse fechada. Seria a redução das despesas superior às receitas que deixariam de ser auferidas com o fechamento da loja? 
Bruno sentiu-se forçado a reconhecer que a demonstração de resultado que apresentou não permitia que respondesse a esta pergunta, mas concluiu que ela era, inegavelmente, importante e precisava ser respondida antes que qualquer decisão em relação à loja Oeste fosse tomada.

Todos concordaram que a reunião fosse interrompida para que Bruno reunisse evidências da contribuição da loja Oeste para os resultados da JBA.

\section{Histórico da empresa}

A JBA Cosméticos Ltda. foi fundada em 1998 por João Alves, Bruno Pacheco e Alice Carvalho. O nome JBA Cosméticos foi escolhido não só por conter as iniciais dos nomes dos três sócios, mas também pensando em futuras campanhas publicitárias, onde o uso dos produtos da JBA seria associado à juventude, beleza e atração, com o slogan "use JBA e mantenha-se Jovem, Bonita e Atraente".

A empresa iniciou suas atividades com a abertura de uma ampla loja em uma rua na Zona Norte do Rio de Janeiro. À medida que os produtos da JBA foram ganhando mercado, o faturamento aumentou e com ele a margem de lucro. Parte desses recursos foi aplicada na expansão da empresa, quatro anos depois, por meio da abertura de mais uma loja própria na Zona Sul do Rio de Janeiro.

Os sócios decidiram, então, que, periodicamente, realizariam pesquisas de mercado e identificariam bairros em que o segmento de cosméticos não estivesse saturado para estabelecer, com segurança, novas lojas. E, depois de inaugurar uma loja, iriam monitorar a satisfação dos clientes e os resultados financeiros para garantir que o novo estabelecimento se consolidasse de forma rentável. Consolidado o novo ponto comercial, o processo seria reiniciado com objetivo de atingir outras localidades no Rio de Janeiro, empregando, para essa finalidade, parte dos lucros da empresa.

Nesse contexto, em 2006, com a bem-sucedida implantação do estabelecimento na Zona Sul, os sócios decidiram abrir mais uma loja e optaram por fazê-lo na Zona Oeste do Rio de Janeiro. Apesar da acirrada concorrência no mercado de cosméticos daquela região, as análises realizadas sugeriram que essa localidade tinha um excelente potencial para a venda desses produtos.

Interessados em viabilizar a expansão sem pressionar, excessivamente, o fluxo de caixa da empresa, os sócios decidiram alugar uma loja, arrendar o mobiliário que seria usado nas instalações, e supri-la com produtos remanejados das outras duas lojas. Assim, ao final de 2006, foi inaugurada a terceira loja da JBA Cosméticos Ltda. na Zona Oeste do Rio de Janeiro.

João Alves era o sócio responsável pela gerência de marketing da empresa. Sua maior preocupação era a satisfação dos clientes e a aceitação dos produtos oferecidos pela JBA Cosméticos. Além disso, controlava os estoques para que não ficassem elevados demais nos momentos de baixa atividade, nem insuficientes nos momentos em que havia alta demanda pelos produtos da empresa.

Apesar de João ser encontrado com mais facilidade na loja Norte, ele visitava as outras duas lojas, ao menos duas vezes por semana, para ter contatos com os clientes, e avaliar se estavam satisfeitos com os produtos e com o atendimento. Também gostava de manter um relacionamento próximo com os funcionários para saber suas opiniões sobre os produtos comercializados, as preferências dos clientes e as condições de trabalho na empresa.

Bruno Pacheco era o sócio responsável pela gerência financeira. Ele cuidava da preparação, análise e interpretação dos relatórios contábeis; de todas as operações com bancos e administradoras de cartões de crédito; e dos recebimentos dos clientes e dos pagamentos aos fornecedores.

Alice Carvalho era a gerente administrativa responsável, principalmente, pela seleção, contratação, treinamento e, quando necessário, remanejamento dos funcionários do escritório central e das lojas. 


\section{Características do mercado de cosméticos}

Em 2010, o mercado nacional de cosméticos estava em franca expansão. Nos últimos anos, a oferta de produtos nacionais de alta qualidade destinados ao público feminino de todos os níveis de renda havia aumentado significativamente. $\mathrm{E}$ as vendas crescentes vinham demonstrando que esse público realmente valorizava os produtos nacionais.

Especialistas afirmavam que o mercado de cosméticos era um bom termômetro do que estava acontecendo com a renda da população. Com a melhor distribuição de renda, os padrões de gastos estavam se alterando. O que parecia caro e de difícil acesso para os consumidores de baixa renda, deixou de ser, e produtos que antes eram considerados supérfluos passaram a ser adquiridos regularmente.

De acordo com dados da Associação Brasileira da Indústria de Higiene Pessoal, Perfumaria e Cosméticos (Abihpec), a indústria brasileira de higiene pessoal, perfumaria e cosméticos apresentou um crescimento médio deflacionado, composto de $10,5 \%$ nos últimos 15 anos, passando de um faturamento líquido dos impostos sobre vendas de R $\$ 4,9$ bilhões em 1996 para R $\$ 27,3$ bilhões em 2010 (Figura 1).

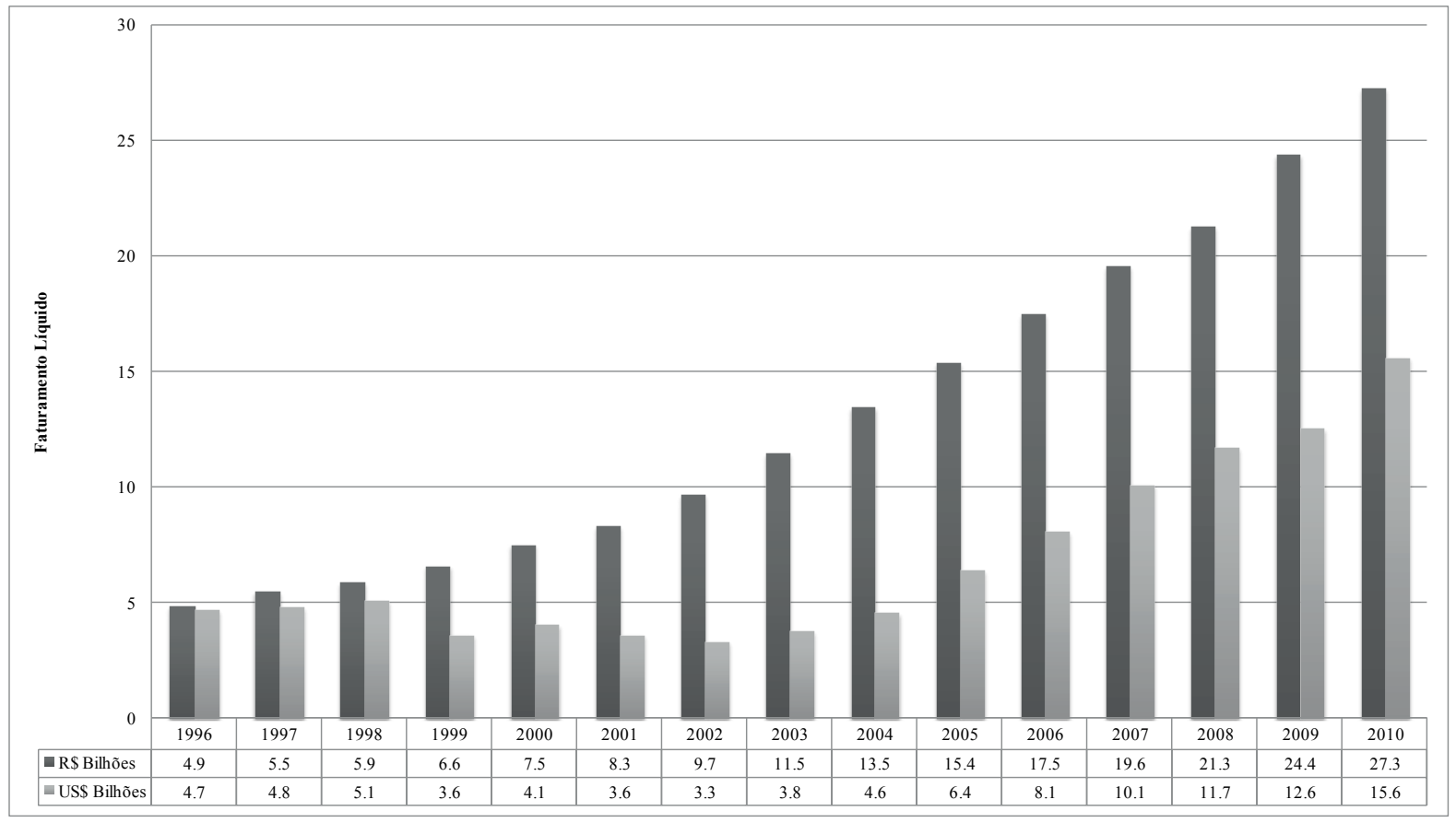

Figura 1. Faturamento Líquido da Indústria de Higiene Pessoal, Perfumaria e Cosméticos.

Fonte: Associação Brasileira da Indústria de Higiene Pessoal, Perfumaria e Cosméticos (Abihpec).

Em 2010, existiam no Brasil 1.659 empresas atuando no mercado de produtos de higiene pessoal, perfumaria e cosméticos, sendo que entre elas havia 20 empresas de grande porte, com faturamento líquido acima dos $\mathrm{R} \$ 100$ milhões, representando $73 \%$ do faturamento do setor.

O grande temor de João e de Alice era fechar a loja Oeste e, com isso, perder a chance de aproveitar o ótimo momento vivido pelo setor. Na opinião deles, repensar as operações dessa loja era preferível a fechá-la. Bruno, porém, achava que manter a loja aberta era uma decisão que acabaria custando caro para os três.

As discussões entre eles começaram a se tornar frequentes e cada vez mais ácidas, ameaçando, inclusive, a grande amizade que sempre tiveram, e a estabilidade da sociedade. Por esse motivo, concluíram que, para o bem de todos e da empresa, precisavam se reunir e decidir, com urgência, se a loja seria mantida ou se seria fechada. Essa reunião foi agendada para os primeiros dias de 2011, logo após os feriados do fim do ano. 


\section{Situação financeira da JBA Cosméticos Ltda.}

Após a reunião com João e Alice, Bruno pediu a seus funcionários que analisassem as despesas da empresa, classificando-as em dois grupos. No primeiro deveriam ser incluídas as despesas claramente vinculadas a cada uma das lojas em separado e, no segundo, as despesas que seriam comuns às três lojas.

As Tabelas 2 e 3, preparadas pela equipe de Bruno, retratam, respectivamente, as despesas de vendas, e as despesas administrativas incorridas em 2010 pela JBA Cosméticos Ltda.

Tabela 2

Detalhamento das despesas de vendas

\begin{tabular}{lcrrr}
\hline Despesas de vendas & Total & Loja Oeste & Loja Sul & Loja Norte \\
\hline Salário - vendedores & 956.000 & 280.000 & 356.000 & 320.000 \\
\hline Propaganda direta & 748.000 & 204.000 & 288.000 & 256.000 \\
\hline Propaganda geral & 180.000 & 43.200 & 72.000 & 64.800 \\
\hline Aluguel de loja & 1.200 .000 & 340.000 & 480.000 & 380.000 \\
\hline Depreciação de móveis da loja & 45.600 & & 24.000 & 21.600 \\
\hline Aluguel do mobiliário da loja & 18.400 & 18.400 & & 28.000 \\
\hline Salário - pessoal de entrega & 84.000 & 28.000 & 28.000 & 12.000 \\
\hline Depreciação de veículos de entrega & 36.000 & 12.000 & 12.000 & 1.082 .400 \\
\hline Despesas totais de vendas & 3.268 .000 & 925.600 & 1.260 .000 & \\
\hline
\end{tabular}

Fonte: Garrison et al. (2007). Adaptado pelos autores

Tabela 3

Detalhamento das despesas administrativas

\begin{tabular}{lccrc}
\hline Despesas administrativas & Total & Loja Oeste & Loja Sul & Loja Norte \\
\hline Salário - gerentes de lojas & 244.000 & 48.000 & 120.000 & 76.000 \\
\hline Salário - pessoal do escritório central & 236.000 & 84.000 & 80.000 & 72.000 \\
\hline Seguro de móveis e estoques & 100.000 & 30.000 & 36.000 & 34.000 \\
\hline Serviços de utilidade pública & 424.000 & 124.000 & 160.000 & 140.000 \\
\hline Encargos sociais & 304.000 & 88.000 & 116.800 & 99.200 \\
\hline Despesas do escritório central - outras & 300.000 & 72.000 & 120.000 & 108.000 \\
\hline Despesas totais administrativas & 1.608 .000 & 446.000 & 632.800 & 529.200 \\
\hline
\end{tabular}

Fonte: Garrison et al. (2007). Adaptado pelos autores.

As despesas de propaganda geral, exibidas na Tabela 2, e as despesas de salário do pessoal e as outras despesas do escritório central, exibidas na Tabela 3, eram comuns às três lojas e foram alocadas às lojas de acordo com as receitas auferidas.

Além das informações constantes nas Tabelas 2 e 3, os funcionários da gerência financeira acrescentaram o seguinte:

a) O contrato de locação do prédio onde a loja Oeste estava poderia ser cancelado a qualquer momento, sem multa.

b) Os móveis e utensílios usados na loja Oeste seriam transferidos às outras lojas, se ela fosse fechada.

c) A gerente geral da loja Oeste seria transferida para o escritório central, caso a loja fosse fechada. Ela ocuparia um cargo para o qual, de qualquer forma, seria contratado um novo funcionário, que receberia $\mathrm{R} \$ 44.000$ por ano. A gerente, porém, manteria seu salário normal, que era de $\mathrm{R} \$ 48.000$ por ano. Os demais funcionários da loja seriam dispensados. 
d) A empresa dispunha de uma equipe de entrega que atendia às três lojas. Um funcionário dessa equipe poderia ser dispensado, se a loja Oeste fosse fechada. O salário dele era de $\mathrm{R} \$ 16.000$ ao ano. Os equipamentos de entrega seriam utilizados nas demais lojas. Embora esses equipamentos não se desgastassem com o uso, eles, eventualmente, se tornariam obsoletos.

e) Os encargos sociais pagos pela empresa correspondiam a $20 \%$ dos salários.

f) Um terço do prêmio de seguro da loja Oeste se referia a móveis e utensílios.

g) Os itens "salários do escritório central" e "despesas do escritório central - outras" relacionavam-se à administração geral da JBA Cosméticos. Se a loja Oeste fosse fechada, um funcionário do escritório central poderia ser dispensado, devido à redução da carga geral de trabalho. A remuneração dele era de $\mathrm{R} \$ 24.000$ por ano.

\section{Questões para discussão}

\subsection{Questão geral}

Considerando que os resultados auferidos em 2010 expressam os valores esperados para os próximos anos, ajude os administradores da JBA Cosméticos a decidir se fecham, ou não, a loja Oeste.

\subsection{Questões específicas:}

1. Quais seriam as reduções nas receitas e nas despesas da JBA, se seus sócios optassem pelo fechamento da loja Oeste? Qual seria o impacto dessa decisão no lucro da JBA?

2. Suponha que, se a loja Oeste fosse fechada, pelo menos um quarto de suas vendas seria transferido à loja Norte, devido à forte fidelidade dos clientes à JBA Cosméticos. Suponha também que a loja Norte teria capacidade para absorver o aumento estimado nas vendas, e que essas vendas adicionais propiciariam a mesma margem bruta percentual auferida na loja Oeste. Que efeito esses fatores teriam em sua recomendação a respeito da loja Oeste? Apresente todos os cálculos utilizados na análise da sua decisão.

3. Quais os principais aspectos não financeiros que deveriam ser considerados na decisão de fechar ou manter a loja Oeste?

\section{Notas de Ensino}

\subsection{Objetivos educacionais}

Este caso se baseia no exercício 13.18, proposto por Garrison, Noreen e Brewer (2007, pp. 519-520) e tem como objetivo ilustrar o uso de conceitos e de técnicas de custos relevantes para análise de decisões políticas de longo prazo. Ele foi concebido para ser usado nas disciplinas de Contabilidade Gerencial ou Contabilidade de Custos nos cursos de graduação e de pós-graduação lato sensu em Ciências Contábeis, em Administração e em Engenharia da Produção. 


\subsection{Arcabouço teórico}

\subsubsection{Custos relevantes para análise de decisões}

No desempenho de suas atividades, administradores frequentemente precisam ponderar sobre opções, fazer escolhas e tomar decisões. Jiambalvo (2009) afirma que, para essa finalidade, eles devem comparar os ganhos esperados com as decisões (receitas incrementais ou economias de custos) com os custos que delas resultarão. Surge assim a preocupação em identificar os custos relevantes para a análise de decisões.

Jiambalvo (2009) ensina que, para analisar decisões, os custos devem ser classificados em duas categorias. Na primeira, estão os custos incrementais - custos que variam com as decisões tomadas e, por isso, relevantes para as decisões; e, na segunda, os custos irrecuperáveis - custos já incorridos, irreversíveis ou que não diferem quando se comparam as opções e, portanto, irrelevantes para as decisões. Ele conclui que, do ponto de vista financeiro, uma opção desejável propicia ganhos esperados superiores aos custos incrementais. Os custos irrecuperáveis não devem ser incluídos nas análises.

A definição de custos incrementais naturalmente suscita a dúvida de quais são os seus elementos. E a resposta que Jiambalvo (2009) e outros autores dão é que os elementos dependerão basicamente da magnitude e do horizonte de tempo das decisões. Os custos incrementais de decisões de reduzida magnitude e/ou de curto prazo (produzir e vender mais uma unidade para pronta entrega, por exemplo) são integrados somente por custos variáveis. Os custos incrementais de decisões de grande envergadura (que trazem mudanças substanciais nas atividades das empresas, mesmo que em curto prazo) e/ou de longo prazo incluem custos fixos incrementais, além dos custos variáveis.

\subsubsection{Outra versão para os mesmos conceitos}

Shillinglaw (1963) oferece uma versão muito particular e interessante para a questão dos custos relevantes para a análise de decisões. Segundo ele, há três tipos de decisões, e para cada um deles um modelo de análise apropriado. No primeiro, estão as decisões operacionais de curto prazo. Os custos relevantes para analisá-las são os custos marginais, aproximados, na prática, pelos custos variáveis médios. No segundo, estão as decisões de investimento que impõem desembolsos em um ou mais períodos para obtenção de recebimentos em diferentes períodos futuros de tempo. Para analisá-las, é necessário usar modelos de fluxos de caixa descontados. Por fim, no terceiro, encontram-se as decisões políticas de longo prazo, que ele denomina de quantitative policy decisions.

As decisões políticas de longo prazo, segundo este autor, envolvem respostas contínuas para problemas recorrentes. Elas abrangem, por exemplo, o estabelecimento de políticas de entrega, de descontos e de seleção de clientes. Essas decisões não demandam desembolsos antecipados para que ganhos futuros sejam auferidos, tal como as decisões operacionais de curto prazo, mas envolvem compromissos de longo prazo, assim como as decisões de investimento.

Segundo Shillinglaw (1963), os custos relevantes para analisar as decisões políticas de longo prazo são os custos atribuíveis: "custos... que seriam evitados, em média, se um produto ou função fosse descontinuado completamente sem que houvesse mudança na estrutura de suporte da organização (p. 80)". Eles representam uma tentativa de operacionalizar de maneira prática o conceito de custos marginais de longo prazo. Os custos atribuíveis incluem os custos variáveis de curto prazo, os custos fixos divisíveis e os custos indivisíveis identificados.

A expressão custos indivisíveis identificados é a tradução que se decidiu dar para a expressão indivisible traceable costs, usada no texto original, porque ela expressa com propriedade que esses custos "são determináveis, prováveis, e suas origens podem ser investigadas" (Michaellis/UOL) e, por serem indivisíveis e relevantes, esses custos eventualmente precisam ser alocados aos produtos ou funções. De fato, Shilliglaw (1963) deixa claro que há casos em que mesmo os custos fixos divisíveis precisam ser alocados. 
Voltando à questão da determinação dos custos atribuíveis após alguns anos, Shillinglaw (1982) comentou que ela requer que cada elemento dos custos indiretos seja estudado para se decidir o quanto dele deverá ser incluído no custo dos produtos e dos serviços. E reconhece que essa não é uma tarefa fácil, e que os resultados estarão sempre sujeitos a críticas. Mesmo assim, ele se disse convencido de que a relevância para os gerentes é um critério de julgamento mais defensável nesse caso do que a precisão matemática. Afinal, o conceito de custos atribuíveis foi concebido para uso gerencial, e os gerentes sempre podem questionar a lógica que sustenta os valores de custos que lhes são fornecidos.

De forma propositada, o caso da JBA Cosméticos apresenta a decisão de manter ou fechar a loja Oeste como uma decisão política de longo prazo. O leitor deve observar que os administradores da empresa assumiram o compromisso de vender cosméticos em longo prazo por meio de uma loja que abriram na Zona Oeste do Rio de Janeiro sem fazer nenhum investimento. E não terão que fazer nenhum investimento para auferir os benefícios que, por acaso, resultarem do fechamento da loja. A loja, os móveis e os equipamentos foram arrendados, e os produtos foram transferidos das demais lojas. Ademais, o contrato de aluguel da loja permite que os administradores possam simplesmente deixá-la a qualquer momento, sem multa; e não há no caso qualquer menção a indenizações que sejam devidas aos funcionários que porventura forem demitidos. Por conseguinte, a análise financeira da decisão de fechar a loja deverá comparar a redução esperada na receita com os custos atribuíveis à loja.

O artigo de Shillinglaw (1963), embora bastante objetivo e claro, é um ensaio teórico que, muito provavelmente, exigirá um substancial esforço de interpretação dos alunos, se eles tiverem que consultá-lo para compreender o conceito de custos atribuíveis e aplicá-lo na análise do caso. Por isso, recomenda-se que se ofereçam aos alunos textos mais didáticos, individualmente ou em caráter complementar, que expliquem o conceito de custos atribuíveis, e apresentem exemplos que ilustrem como eles devem ser apurados e utilizados e, se possível, comentem sobre situações reais onde eles foram ou poderiam ter sido utilizados. As próximas seções resumem e avaliam o conteúdo de três textos que têm essas características.

\subsubsection{A contabilidade de custos chega à indústria de serviços}

Dearden (1978) descreve, em um artigo simples e direto, um modelo para avaliar a rentabilidade de produtos e serviços, que é bastante similar ao modelo proposto por Shillinglaw (1963). Ele define a rentabilidade de um produto (ou serviço) como o decréscimo que haveria no lucro, caso esse produto (ou serviço) não tivesse sido fabricado e vendido. Para apurá-la, aconselha que se compare a receita auferida com a venda do produto (ou serviço) com os custos unicamente atribuíveis a ele. Esses custos são, na sua interpretação, os únicos custos relevantes. Os demais custos, que denominou de custos conjuntos, ele considera irrelevantes. Dessa forma, conclui que a medida relevante da rentabilidade de produtos ou serviços é o quanto contribuem para cobrir os custos conjuntos e formar o lucro.

Os custos unicamente atribuíveis a um produto ou serviço são definidos por Dearden (1978) como aqueles que seriam suprimidos, caso esses produtos ou serviços fossem eliminados.

Deve-se ressaltar que Dearden (1978) advertiu, em sua argumentação, que a simplicidade e a clareza sugeridas na definição dos custos unicamente atribuíveis são ilusórias. E deu a entender que parte dos custos unicamente atribuíveis deverá ser determinada por meio de alocações que envolvem algum grau de subjetividade, mas evitou explorar essa questão mais detalhadamente.

Se há algo que falta ao texto de Dearden (1978) é o esclarecimento de que o modelo que propõe não pode ser usado quando houver investimentos envolvidos. Se houver a avaliação da rentabilidade, terá que ser feita por meio de métodos de fluxos de caixa descontados e, não, da margem de contribuição, como sugere. 


\subsubsection{Margem de contribuição, custos fixos identificados e retorno sobre o investimento}

Esta seção recebeu o título do Capítulo 18 do livro escrito por Martins (2010) onde ele propõe que há custos fixos que não podem nem devem ser ignorados na análise da rentabilidade de produtos e serviços. Ele denomina esses custos de fixos identificados, e recomenda que a rentabilidade de produtos, de serviços ou de unidades operacionais das empresas seja avaliada através de duas margens de contribuição. A primeira é obtida pela diferença entre a receita total e os custos variáveis, e mede a contribuição da receita para a cobertura dos custos fixos e para a formação do lucro. A segunda é obtida pela diferença entre a primeira margem de contribuição e os custos fixos identificados (de produtos, de serviços, ou de unidades operacionais), e mede a contribuição da receita para a cobertura dos custos fixos comuns e para a formação do lucro.

Martins (2010) esclarece que a medida relevante da rentabilidade de um produto, de um serviço, ou de uma unidade operacional é a segunda margem de contribuição, mas não se preocupa em explicar em que condições ela deve ser usada.

Não obstante a medida de rentabilidade relevante e os conceitos usados por Martins (2010) sejam muito parecidos com as medidas e conceitos encontrados nos artigos de Shillinglaw (1963) e de Dearden (1978), ele nada comenta sobre a necessidade de se alocar parte dos custos para se avaliar a rentabilidade de produtos e serviços em longo prazo, dando a entender que uma das vantagens do modelo que propõe é que ele está livre das arbitrariedades que acompanham a alocação de custos indiretos.

\subsubsection{Relatórios por segmento e descentralização}

Garrison et al. (2007) ${ }^{1}$ tratam da avaliação de desempenho dos segmentos de uma empresa e da decisão de fechá-los em dois capítulos distintos (12 e 13) e adotam uma abordagem que é concomitantemente simples e tecnicamente correta. De fato, reproduzem a proposta do Shillinglaw (1963) de forma bastante didática.

Para esses autores, a margem do segmento é a medida adequada da rentabilidade de um segmento de uma empresa (uma loja, um território de venda ou um cliente). Ela é determinada conforme mostrado na Tabela 4.

Tabela 4

Determinação da Margem de Segmento

\begin{tabular}{lccc} 
& & & \\
\cline { 2 - 4 } & Segmento 1 & Segmento 2 & Empresa \\
\hline Receita de Vendas & $\mathrm{xxx}$ & $\mathrm{xxx}$ & $\mathrm{xxx}$ \\
\hline Menos Custos Variáveis & $\mathrm{xxx}$ & $\mathrm{xxx}$ & $\mathrm{xxx}$ \\
\hline Margem de Contribuição & $\mathrm{xxx}$ & $\mathrm{xxx}$ & $\mathrm{xxx}$ \\
\hline Menos Custos Fixos Vinculáveis & $\mathrm{xxx}$ & $\mathrm{xxx}$ & $\mathrm{xxx}$ \\
\hline Margem do Segmento & $\mathrm{xxx}$ & $\mathrm{xxx}$ & $\mathrm{xxx}$ \\
\hline Menos Custos Fixos Comuns & & & $\mathrm{xxx}$ \\
\hline Lucro Operacional Líquido & & & $\mathrm{xxx}$ \\
\hline
\end{tabular}

Fonte: Sugerido por Garrison et al. (2007) e adaptado pelos autores.

1 Em 2013 foi publicada no Brasil uma edição mais recente do livro escrito por esses autores (Garrisson, Noreen e Brewer (2013)). 
A margem de contribuição informa o aumento no lucro que resulta de variações no volume de atividades (vendas) e é, particularmente, útil para analisar usos temporários da capacidade (decisões operacionais de curto prazo), como no caso de atender a pedidos especiais (Garrison et al. (2007), p. 449).

Os custos fixos vinculáveis ${ }^{2}$ a um segmento são custos fixos incorridos por causa da existência do segmento - se o segmento nunca tivesse existido, esses custos não teriam sido incorridos; e se o segmento fosse eliminado, esses custos seriam suprimidos. Em uma situação real, às vezes é difícil saber se um custo deve ser classificado como vinculável ou não. Em alguns casos, a determinação desses custos terá que ser baseada em alocações, com variados graus de subjetividade (Garrisson et al. (2013), p. 449/450).

Os custos fixos comuns sustentam as operações de mais de um segmento, mas não são vinculáveis, no todo ou em parte, a nenhum deles. Isto é, esses custos não serão eliminados pela exclusão dos segmentos individualmente (Garrisson et al. (2013), p. 450). Logo, são irrelevantes para analisar a rentabilidade dos segmentos.

A margem do segmento mede o quanto ele contribuí para a cobertura dos custos comuns e formação do lucro e é "a melhor medida da rentabilidade de um segmento no longo prazo" (Garrison et al. (2007), p. 451).

No Capítulo 13 do livro, Garrison et al. (2007) tratam claramente da decisão de eliminar um segmento como uma decisão política de longo prazo e indicam que a margem do segmento é o critério financeiro adequado para analisar essa decisão. Concluem ainda que essa margem deve ser comparada àquelas que seriam obtidas em opções mais rentáveis, em uma evidente alusão aos custos de oportunidade.

Tomando como referência o modelo de Shillinglaw (1963), o que falta aos ensinamentos de Garrison et al. (2007) é mostrar que a margem de segmento não deve ser usada para analisar decisões que envolvam investimentos.

\subsection{Sugestão para um plano de ensino}

Este caso foi projetado para ser utilizado em sessão de noventa minutos, para discutir conceitos e técnicas de custos relevantes para análise de decisões políticas de longo prazo. A sessão deve ser realizada, preferencialmente, com uma turma já familiarizada com tópicos básicos de custos, uma vez que a discussão demanda conhecimentos teóricos sobre conceitos e classificações de custos, e sobre análise incremental.

Para evitar que os alunos usem a sessão para expressar suas opiniões pessoais sobre o caso (por exemplo, "eu acho que...") ou tentem se concentrar somente nas contas que precisam ser feitas, sugere-se que este caso seja entregue com antecedência, para que eles o analisem individualmente e consultem a bibliografia indicada no fim deste documento. É interessante também que o professor incentive os alunos a procurarem notícias recentes de empresas comerciais que foram obrigadas a fechar lojas, para ver que fatores as levaram a essa situação e, se possível, observar como seus administradores tomaram a decisão de liquidação das unidades.

A título de exemplo, há o artigo publicado por Naiditch (2006) na revista Exame, que mostra que, em 2006, os administradores das Casas Bahia precisaram rever suas prioridades, fechar lojas e demitir funcionários. Segundo a jornalista, a decisão foi motivada pela constatação de que a expansão realizada no período imediatamente anterior não tinha sido feita com os cuidados requeridos. Lojas com tamanho apropriado para grandes centros foram abertas em cidades pequenas do interior, em uma época em que a retração na economia dessas cidades reduziu as vendas do comércio em geral e aumentou os índices de inadimplência, comprometendo a rentabilidade das Casas Bahia, e forçando seus administradores a reconsiderarem seus planos de expansão.

2 É importante destacar que o professor Antonio Zoratto Sanvicente, tradutor do livro de Garrison, Noreen, e Brewer (2007), traduziu a expressão traceable fixed costs como custos fixos vinculáveis. Essa opção preserva o sentido original do conceito e, demais, estabelece, com propriedade, a proximidade dele com o conceito de attributable costs proposto por Shillinglaw (1963), traduzido aqui como custos atribuíveis. 
Os primeiros trinta e cinco minutos da sessão podem ser dedicados à discussão do caso em pequenos grupos. Encerrada essa etapa, o professor poderá aproveitar os resultados alcançados para construir com a turma a análise do caso, com os esclarecimentos e correções cabíveis.

Recomenda-se que a discussão em sala seja iniciada com uma consulta genérica à turma: "Quantos acham que a loja Oeste deve ser fechada?”. Dessa forma, os alunos serão incentivados a defenderem suas decisões com mais empenho.

Apurado o número de alunos que são favoráveis ao fechamento, pode-se questionar o que levaria os administradores de uma rede de lojas a cogitar o fechamento de uma delas num momento em que as vendas do setor estão crescendo.

Uma vez que essas questões sejam suficientemente exploradas, sugere-se que os professores mostrem as informações da Tabela 1, apontem o prejuízo incorrido com a loja Oeste, e perguntem se o fechamento da loja faria o lucro da empresa aumentar em $\mathrm{R} \$ 104.400,00$ (prejuízo incorrido pela loja Oeste). As respostas mostrarão as limitações das informações fornecidas na Tabela 1 e levarão os alunos a perceberem que os lucros reportados para as lojas não medem a contribuição que elas dão individualmente para o lucro da empresa. Sendo assim, o próximo passo é questionar como medir a contribuição de cada loja para a empresa. Essa é a oportunidade para usar a questão específica n. ${ }^{\circ} 1$ (Quais seriam as reduções nas receitas e nas despesas da JBA, se seus sócios optassem pelo fechamento da loja Oeste? Qual seria o impacto dessa decisão no lucro da JBA?) para fazer os alunos refletirem sobre o conceito de lucro atribuível ou de margem do segmento.

Destaca-se que essa lógica foi adotada por Dearden (1978) para justificar a classificação dos custos totais em custos exclusivos (diretos ou unicamente atribuíveis) ou em custos conjuntos e usá-la para apurar a margem direta, que, segundo ele, é a medida apropriada da rentabilidade dos produtos ou serviços.

A questão específica n. ${ }^{\circ} 2$ pode ser usada, a critério dos professores, para comentar que a contabilidade não consegue medir corretamente os resultados de unidades interdependentes, como é o caso das lojas Oeste e Norte. Como há evidências de que há clientes que fazem suas compras em ambas as lojas, a expectativa é que a redução da receita pelo fechamento da loja Oeste seja inferior ao valor da receita da loja exibida na Tabela 1.

A questão específica n. 3 foi proposta para lembrar que as informações financeiras são importantes, mas devem ser usadas com discernimento e ponderação.

Para concluir a sessão, sugere-se que os professores façam uma breve avaliação dos trabalhos, apontando os objetivos do caso, os principais conceitos e técnicas usados e as principais conclusões alcançadas.

\subsubsection{Análise das possíveis alternativas de decisões do caso}

O caso da JBA Cosméticos remete os alunos a uma situação na qual eles devem analisar se fecham ou mantêm uma das lojas da empresa. As informações fornecidas foram selecionadas propositadamente para que essa decisão tenha as características de uma decisão política de longo prazo, tal como definida por Shillinglaw (1963). Dessa forma, a avaliação deverá envolver a comparação da receita da loja com os custos que lhe são atribuíveis. No entanto, a demonstração de resultado que é fornecida no caso foi elaborada com base na completa alocação de todos os custos da empresa a todas as lojas, e os custos comuns foram distribuídos com base nas vendas.

A alocação indiscriminada de todos os custos a todas as lojas com base nas vendas superestima o valor dos custos atribuíveis à loja cujo desempenho está em questão, dando a impressão errônea de que ela é deficitária.

A correta utilização das informações fornecidas por Bruno, o gerente financeiro, para calcular os custos atribuíveis mostrará que o fechamento da loja, na realidade, reduzirá o lucro da empresa, e, portanto, é indesejável. 
Há nos esclarecimentos de Bruno a alusão a um funcionário do escritório central que será demitido se a loja for fechada, para lembrar que a proximidade não é um critério para se determinar os custos atribuíveis, e ensejar que os professores comentem que nem sempre a realidade é clara e objetiva como descrita no caso. É por isso que alocações subjetivas de custos indiretos são necessárias, na apuração dos custos atribuíveis, tal como sugerido por Shillinglaw (1963 e 1982), Dearden (1978), e Garrison et al. (2007).

A breve revisão dos quatro textos indicados evidencia que o artigo de Shillinglaw (1963) é o que fornece as orientações mais qualificadas para a análise do caso. Contudo, é bastante provável que o seu valor não seja adequadamente reconhecido pelos alunos e até por alguns professores, afinal, é um texto publicado em 1963 que adota uma linha de argumentação que exigirá uma leitura mais demorada para ser compreendida.

Para superar essas dificuldades, os professores poderão recomendar textos mais didáticos como o artigo de Dearden (1978), o Capítulo 18 do livro de Martins (2010) e os Capítulos 12 e 13 do livro de Garrison et al. (2007). Esses dois últimos capítulos são os que tratam de forma mais elaborada e didática as decisões de políticas de longo prazo.

Recomenda-se que os professores incentivem os alunos a refletirem sobre os problemas de se decidir sobre o fechamento de uma loja simplesmente por meio de uma analise financeira feita com os dados de um único período, ainda que esses dados expressem tendências de longo prazo. A oportunidade para isso está na segunda questão do caso. Ela inicia com a suposição de que, se a loja Oeste fosse fechada, pelo menos um quarto de suas vendas seria transferido à loja Norte, devido à forte fidelidade dos clientes à JBA Cosméticos.

A apresentação formal dessa suposição permite que os professores comentem que a receita de uma loja não é necessariamente um bom indicador dos ganhos gerados por ela. A possibilidade de os clientes de uma loja eventualmente fazerem suas compras nas demais lojas da rede demonstra que a margem do segmento de uma loja pode superestimar as perdas decorrentes da sua eliminação. Aliás, é fundamental ressaltar que, em geral, as medidas contábeis não são indicadores de desempenho apropriados quando há interdependências entre os segmentos. Isso pode ser ilustrado pela referência ao fato de que há empresas comerciais que mantêm stands ou lojas simplesmente para divulgar seus produtos e serviços (lojas conceito). Essas lojas não têm receitas, e seus custos beneficiam as empresas, os produtos que elas vendem e as demais lojas. Nesses casos, as vendas das demais lojas não resultam apenas do trabalho dos seus vendedores, e os custos que lhes são atribuídos pela contabilidade são inferiores aos que lhes caberiam pelo uso que fazem dos recursos das empresas (a menos, é claro, que haja a alocação dos custos das lojas conceito para as demais).

Por fim, sugere-se que os professores mostrem aos alunos que há fatores qualitativos relevantes que precisam ser considerados na avaliação do fechamento de uma loja, e que não podem ser tratados pela contabilidade simplesmente porque não podem ser expressos em termos financeiros, ou pelas próprias limitações dos métodos que a contabilidade emprega.

\subsection{Possíveis respostas às questões específicas}

\subsubsection{Quais seriam as reduções nas receitas e nas despesas da JBA se seus sócios optassem pelo fechamento da loja Oeste? Qual seria o impacto dessa decisão no lucro da JBA?}

A demonstração de resultados para o exercício findo em 31/12/2010, que está na Tabela 1 e expressa os valores esperados para os próximos anos, indica que a JBA é uma empresa rentável, mas a loja Oeste não. Ela obteve naquele ano um prejuízo de $\mathrm{R} \$ 104.400,00$. Esse prejuízo, no entanto, resultou da distribuição dos custos comuns a todas as lojas, com base no valor das vendas que realizaram.

Para demonstrar que o prejuízo apurado não representa o resultado da loja Oeste basta que se determine a variação esperada no lucro da JBA, caso a loja Oeste seja fechada. Essa demonstração encontra-se na Tabela 5. 
A demonstração da Tabela 5 evidencia que, se a loja for fechada, a JBA deixará de auferir $\mathrm{R} \$ 2.880 .000$ de receitas, mas somente conseguirá uma redução de $\mathrm{R} \$ 2.680 .000$ nos custos. Logo, seu lucro reduzirá em $\mathrm{R} \$ 200.000,00$, o que mostra que o fechamento, a princípio, não é recomendável.

Esse resultado poderia ser obtido de forma aproximada se Bruno analisasse regularmente o resultado das lojas e da JBA de acordo com o modelo proposto por Shillinglaw (1963,1982), Dearden (1978) e Garrison et al. (2007).

Tabela 5

Impacto do fechamento da loja Oeste no resultado da JBA Cosméticos

\begin{tabular}{lr}
\hline Vendas da loja Oeste & $2.880 .000,00$ \\
\hline Custos atribuíveis & $1.612 .800,00$ \\
\hline Custo dos produtos vendidos & $280.000,00$ \\
\hline Salários - vendedores & $204.000,00$ \\
\hline Propaganda direta & $340.000,00$ \\
\hline Aluguel da loja & $16.000,00$ \\
\hline Salários - pessoal de entrega & $(4.000,00)$ \\
\hline Salários - pessoal do escritório central & $24.000,00$ \\
\hline Salários - pessoal do escritório central & $56.000,00$ \\
\hline Encargos sociais - vendedores & $3.200,00$ \\
\hline Encargos sociais - pessoal de entrega & $(800,00)$ \\
\hline Encargos sociais - pessoal do escritório central & $4.800,00$ \\
\hline Encargos sociais - pessoal do escritório central & $20.000,00$ \\
\hline Seguro de móveis e estoques & $124.000,00$ \\
\hline Serviços de utilidade pública & $2.680 .000,00$ \\
\hline (-) Total dos custos atribuíveis líquidos & 200.000 .00 \\
\hline (=) Redução no lucro pelo fechamento da loja Oeste
\end{tabular}

Fonte: Elaborado pelos autores.

A Tabela 6 mostra as margens das lojas e o lucro operacional líquido da JBA Cosméticos determinados segundo o modelo proposto pelos referidos professores.

A demonstração de resultado apresentada na Tabela 6 evidencia que a loja Oeste é a que menos contribui para a cobertura dos custos comuns, mas o seu fechamento não é desejável. Ele teria como consequência uma redução de $\mathrm{R} \$ 111.600,00$ nos lucros da JBA.

A diferença que há entre os valores constantes nas Tabelas 5 e 6 são decorrentes do fato de a Tabela 5 ter sido construída de acordo com as considerações feitas por Bruno; e a Tabela 6 ter sido montada por meio da simples reorganização dos dados das Tabelas 1, 2 e 3.

As informações das Tabelas 5 e 6 talvez devessem ser utilizadas para estudar a possibilidade de aumentar as vendas e a margem dos produtos vendidos na loja Oeste, e/ou reduzir os custos que lhes são atribuíveis. Isso, no entanto, demandaria o empenho dos administradores da JBA e da gerente da loja Oeste. Essas questões são tratadas no capítulo 12 do livro de Garrison et al. (2007). 
Tabela 6

Demonstração de resultados para o exercício findo em 31/12/2010 (reorganizada)

\begin{tabular}{|c|c|c|c|c|}
\hline & & & & \\
\hline & Total & Oeste & Sul & Norte \\
\hline Vendas & $12.000 .000,00$ & $2.880 .000,00$ & $4.800 .000,00$ & $4.320 .000,00$ \\
\hline Custo dos produtos vendidos & $6.628 .800,00$ & $1.612 .800,00$ & $2.640 .000,00$ & $2.376 .000,00$ \\
\hline Lucro Bruto & $5.371 .200,00$ & $1.267 .200,00$ & $2.160 .000,00$ & $1.944 .000,00$ \\
\hline \multicolumn{5}{|l|}{ Custos Atribuíveis } \\
\hline Salário - gerentes de lojas & $244.000,00$ & $48.000,00$ & $120.000,00$ & $76.000,00$ \\
\hline Salário - pessoal de entrega & $84.000,00$ & $28.000,00$ & $28.000,00$ & $28.000,00$ \\
\hline Salário - vendedores & $956.000,00$ & $280.000,00$ & $356.000,00$ & $320.000,00$ \\
\hline Encargos sociais & $256.800,00$ & $71.200,00$ & $100.800,00$ & $84.800,00$ \\
\hline Propaganda direta & $748.000,00$ & $204.000,00$ & $288.000,00$ & $256.000,00$ \\
\hline Aluguel das lojas & $1.200 .000,00$ & $340.000,00$ & $480.000,00$ & $380.000,00$ \\
\hline Depreciação de móveis da loja & $45.600,00$ & & $24.000,00$ & $21.600,00$ \\
\hline Aluguel do mobiliário da loja & $18.400,00$ & $18.400,00$ & & \\
\hline Depreciação de veículos de entrega & $36.000,00$ & $12.000,00$ & $12.000,00$ & $12.000,00$ \\
\hline Seguro de móveis e estoques & $100.000,00$ & $30.000,00$ & $36.000,00$ & $34.000,00$ \\
\hline Serviços de utilidade pública & $424.000,00$ & $124.000,00$ & $160.000,00$ & $140.000,00$ \\
\hline Total dos custos atribuíveis & $4.112 .800,00$ & $1.155 .600,00$ & $1.604 .800,0$ & $1.352 .400,00$ \\
\hline Margem das lojas & $1.258 .400,00$ & $111.600,00$ & $555.200,00$ & $591.600,00$ \\
\hline \multicolumn{5}{|l|}{ Custos Comuns } \\
\hline Propaganda geral & $180.000,00$ & & & \\
\hline Salário - pessoal do escritório central & $236.000,00$ & & & \\
\hline Encargos sociais & $47.200,00$ & & & \\
\hline Despesas do escritório central - outras & $300.000,00$ & & & \\
\hline Total dos custos comuns & $763.200,00$ & & & \\
\hline Lucro operacional líquido & $495.200,00$ & & & \\
\hline
\end{tabular}

Fonte: Elaborado pelos autores.

7.4.2 Suponha que, se a loja Oeste fosse fechada, pelo menos um quarto de suas vendas seria transferido à loja Norte, devido à forte fidelidade dos clientes à JBA Cosméticos. Suponha também que a loja Norte tenha capacidade para absorver o aumento estimado nas vendas, e que essas vendas adicionais propiciariam a mesma margem bruta percentual auferida na loja Oeste. Que efeito esses fatores teriam em sua recomendação a respeito da loja Oeste? Apresente todos os cálculos utilizados na análise da sua decisão.

A demonstração da Tabela 5 mostra que o fechamento da loja Oeste nos termos previstos por Bruno reduzirá o lucro da JBA Cosméticos em $\mathrm{R} \$ 200.000,00$. Contudo, se um quarto das vendas dessa loja for transferido para a loja Norte sem que haja alteração nas margens brutas dos produtos vendidos, e sem que a loja Norte e a JBA incorram em novos custos, a redução no lucro da JBA será compensada por um aumento no lucro bruto da loja Norte no valor de $\mathrm{R} \$ 316.800,00$ (vendas de $\mathrm{R} \$ 720.000,00$ menos custos dos produtos vendidos de $\mathrm{R} \$ 403.200,00)$. Nesse caso, o lucro da JBA crescerá em $\mathrm{R} \$ 116.800,00$.

Enfim, a possibilidade de transferência das vendas da loja Oeste para a loja Norte nas condições apresentadas na questão torna o fechamento desejável. 


\subsubsection{Quais os principais aspectos não financeiros que deveriam ser considerados na decisão de fechar ou manter a loja Oeste?}

Essa é uma questão aberta que cria oportunidades para que os professores explorem o caso da maneira que lhes parecer mais apropriada.

Se os alunos realmente pesquisaram revistas e jornais de negócios e trouxeram histórias de empresas que, em algum momento, tiveram que fechar lojas, eles poderão explicar que motivos levaram essas empresas a reduzirem suas redes de lojas, e como os administradores dessas empresas decidiram que lojas deveriam ser fechadas.

Com certeza, surgirão nos relatos os fatores não financeiros que foram considerados nos fechamentos das lojas, e que foram cotejados com as análises financeiras para dar origem às decisões tomadas.

Sem ter a pretensão de esgotar o assunto, são listados a seguir alguns exemplos:

a) A loja Modern Sound, uma referência na venda de discos no Rio de Janeiro, encerrou suas operações em 2010, por não ter conseguido sobreviver às transformações ocorridas na comercialização de músicas. Pedro Otávio, filho do fundador da loja, afirmou que "além da grande rede e da pirataria física, a política de vendas praticada pela indústria do disco a partir dos anos 90" favoreceu os supermercados e as lojas de departamento, e contribuiu decisivamente para o fechamento das pequenas lojas de rua (Miguel, 2010).

b) A Grande Rio Comércio de Veículos Ltda., concessionária da Honda Automóveis do Brasil S/A no Maranhão, (Henrique, 2013) e o Grupo CAOA, que durante algum tempo foi revendedor dos veículos da Hyundai na Paraíba (Notícias Automotivas, 2013), foram obrigados a interromper suas operações comerciais por determinações da Justiça em resposta a processos iniciados por empresas que eles supostamente prejudicaram.

c) Matéria publicada no sítio Brasilagro (2013) informou que se estimava que 168 lojas de grandes varejistas seriam fechadas até o fim de 2013. Foram três os motivos apontados: desempenho abaixo do esperado e sobreposição de lojas; "limpeza" da base de lojas após operações de fusões e aquisições; e, no caso específico da Via Varejo, determinação do Conselho de Defesa Econômica (Cade).

A questão 2, por si, exemplifica um fator não financeiro que não pode ser ignorado. Ela sugere que, se não fosse pela loja Oeste, alguns clientes não teriam experimentado os produtos e serviços da JBA e se tornado leais à empresa. Por outro lado, os administradores da JBA precisam avaliar se a lealdade dos clientes é forte o bastante para levá-los a sair da zona Oeste para a zona Norte em busca dos produtos da empresa. Isso sem contar com a possibilidade de que os concorrentes aproveitem o fechamento da loja para aumentar suas fatias de mercado na região.

\subsubsection{Questão geral: Considerando que os resultados auferidos em 2010 expressam os valores esperados para os próximos anos ajude os administradores da JBA Cosméticos a decidir se fecham, ou não, a loja Oeste.}

Essa questão representa um teste especial para os professores de Contabilidade. Antes de respondê-la, recomenda-se que eles avaliem se cabe, realmente, ao contador de uma empresa a tarefa de dar uma opinião conclusiva sobre o fechamento de uma loja.

Considerando que contadores são assessores especializados dos administradores de qualquer empresa, a melhor ajuda que podem dar aos administradores da JBA é fornecer a eles análises financeiras tecnicamente corretas e mostrar claramente os limites dessas análises. A decisão será sempre dos administradores. 
Dean, Ferris e Konstans (1988) realizaram um levantamento de campo longitudinal com contadores recém-contratados para a controladoria de uma empresa industrial e para uma firma de auditoria nos EUA, e observaram que, passado um ano, algumas das expectativas que esses contadores tinham em relação ao trabalho não se realizaram, e que a frustração dessas expectativas estava negativamente associada ao comprometimento que os contadores expressaram em relação às organizações, às intenções dos contadores de permanecer e participar e, em menor grau, às suas decisões de produzir. Concluíram, então, que o estabelecimento de expectativas realísticas para as tarefas que serão realizadas e para as condições de trabalho que serão encontradas é desejável tanto para os contadores quanto para as empresas que os contratam.

Pode-se argumentar, portanto, que cumpre aos professores de Contabilidade esclarecer aos seus alunos o escopo da função que desempenharão no futuro, evitando que eles tenham expectativas que fatalmente não se realizarão.

\section{Referências}

ABIHPEC - Associação Brasileira da Indústria de Higiene Pessoal, Perfumaria e Cosméticos. Panorama do Setor 2010-2011. Recuperado em 04 de Setembro, 2013, de http://www.abihpec.org.br/wp-content/uploads/2010/11/Microsoft-Word-Panorama-do-setor-2010-2011-14_04_2011.pdf

Brasilagro (2013, Outubro 24) Grandes varejistas estão fechando lojas. Recuperado em 08 de Janeiro, 2014, de http://www.brasilagro.com.br/index.php?noticias/detalhes/8/53724.

Dean, R. G., Ferris, K. R. \& Konstans, C. (1988) Occupational reality shock and organizational commitment: evidence from the accounting profession. Accounting, Organizations and Society, 13(3), pp. 235-250.

Dearden, J. (1978, September/October) Cost accounting comes to service industries. Harvard Business Review, 56(5), pp.132-140.

Henrique, M. (2013, Setembro 27) Justiça fecha loja da Honda em São Luis. O ESTADO. Recuperado em 08 de Janeiro, 2014, de http://www.blogsoestado.com/marciohenrique/2013/09/27/justica-fecha-loja-da-honda-em-sao-luis/

Jiambalvo, J. (2009) Contabilidade gerencial. Rio de Janeiro: LTC.

Garrison, R. H, Noreen, E.W. \& Brewer, P. C. (2007) Contabilidade Gerencial. Rio de Janeiro: LTC.

Garrison, R. H, Noreen, E.W. \& Brewer, P. C. (2013) Contabilidade Gerencial. Porto Alegre: AMGH.

Martins, E. (2010) Contabilidade de Custos. São Paulo: Atlas, 2010.

Michaelis. Dicionário de inglês online. Recuperado em 30 agosto, 2013 de http://michaelis.uol.com.br/moderno/ingles/index.php?lingua=ingles- portugues\&palavra=traceable

Miguel, A. C. (2010, Dezembro 15) Com o iminente fechamento da Modern Sound, o Rio perde sua última grande loja de discos. O Globo. Recuperado em 08 de Janeiro, 2014, de http://oglobo.globo.com/cultura/ com-iminente-fechamento-da-modern-sound-rio-perde-sua-ultima-grande-loja-de-discos-2910862

Naiditch, S. (2006, setembro 21) Dois anos sem crescer. Revista Exame,877. Recuperado em 30 agosto, 2013 de http://exame.abril.com.br/revista-exame/edicoes/0877/noticias/dois-anos-sem-crescer-m0111588.

Notícias Automotivas (2013, Junho 21) CAOA tem que fechar lojas na Grande João Pessoa. Recuperado em 8 Janeiro, 2014, de http://www.noticiasautomotivas.com.br/fiat-grand-siena-serie-especial-sublime-chega-por-r-46-360/

Shillinglaw, G. (1963, spring) The Concept of Attributable Cost. Journal of Accounting Research, 1(1), pp. 73-85. Shillinglaw, G. (1982) Managerial cost accounting. Homewood: Irwin. 